\title{
Deadline Scheduling Algorithms in Cloud Computing: A Review
}

\author{
Himani \\ Department of CSE \\ Guru Nanak Dev University, India
}

\author{
Kamaljit Kaur \\ Assistant Professor \\ Guru Nanak Dev University,India
}

\begin{abstract}
Cloud Computing is the nascent technology which is based on pay-per-use model. It is computing paradigm where applications, data, bandwidth and IT services are provided via Internet. Objective of the cloud service providers to use resource proficiently and achieve the maximum profit. This leads to task scheduling as a core and inspiring issue in cloud computing. Scheduling is the procedure of determining how to oblige resources between a varieties of possible tasks. In this research paper various types of deadline scheduling algorithms that meets the deadline have been surveyed and analyzed. Based on the study of different algorithms, a comparison between them are presented on the basis of different perspectives.
\end{abstract}

Keywords- Cloud Computing, Scheduling, Static and dynamic scheduling algorithm, Virtual Machines.

\section{INTRODUCTION}

Cloud computing an advanced way in which IT infrastructure, applications, services are developed, designed and delivered. In this, the value of IT assets can be expended on the basis of pay-per-use model. Many computing facility providers like Google, Microsoft, IBM, Yahoo etc deliver data centers in several localities around the world to supply Cloud computing services. Cloud computing can be defined as a collection of computing and communication resources located over distributed datacenters; that is shared by many different users [1].

The cloud computing service models are Software as a Service (SaaS), Platform as a Service (PaaS) and Infrastructure as a Service (IaaS). In a Software as a Service model, a pre-made application, along with any required software, operating system, hardware, and network are provided. In PaaS, an operating system, hardware, and network are provided, and the customer installs or develops its own software and applications. The IaaS model provides just the hardware and network; the customer installs or develops its own operating systems, software and applications.

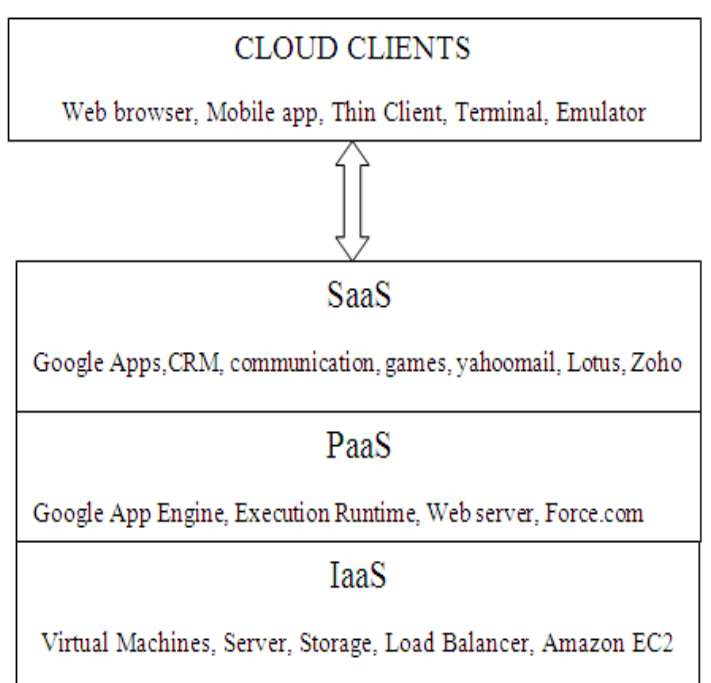

Figure 1 Overview of Cloud Computing

\section{BACKGROUND}

Dr. M. Dakshayini [2] proposed a new scheduling algorithm based on priority and admission control scheme. The priority is assigned to each admitted queue. Admission of each queue is absolute by calculating acceptable delay and service cost. Benefit of proposed policy with the proposed cloud architecture has attained very high $(99 \%)$ service completion rate with sure QoS. As this policy provides the highest preference for very much paid user service-requests, overall examining cost for the cloud also increases. Amit Nathani [3] the proposed algorithm finds number of slots in addition to finding one slot while scheduling a deadline sensitive lease. It also applies two concepts; one is swapping and other is backfilling, while rescheduling already accommodated leases to make space for a newly arrived lease. Backfilling has a disadvantage of requiring more preemption, which increases overall overhead of the system. The results show that by applying swapping and multiple slots concepts, the number of accepted leases increases compared to the existing algorithm. It also shows that the proposed algorithm requires rescheduling of fewer leases compared to the existing algorithm of Haizea. R. Santhosh [4] focus on providing a solution for online scheduling problem of real-time tasks using "Infrastructure as a Service" model offered by cloud computing. The real time tasks are scheduled preemptively with the intent of maximizing the total utility and efficiency. It also minimize the response time and to improve the efficiency of the tasks. The tasks are migrated to another virtual machine whenever a task misses its deadline. This improves the overall system performance and maximizes the total utility. Florin Pop, Ciprian Dobre [5] addresses the 
problem of remote scheduling of a periodic and sporadic tasks with deadline constrains in Cloud computing. Beginning from traditional addressed scheduling techniques and considering asynchronous mechanism to handle tasks, they analyze the possibility of decoupling event listening from task creation and scheduling, activities that can be placed into a peer-peer relation over a network or to client-server in Cloud. They consider multiple independent tasks sources that follow with a specific distribution. They created a simulation experiment in MONARC that highlights the capability of tasks migration in order to respect the deadlines. Nitish Chopra [6] developed a level based scheduling algorithm which executes tasks level wise and it uses the concept of sub-deadline which is helpful in finding best resources on public cloud for cost saving and also completes workflow execution within deadlines. Dr. V. Vaithiyanathan [7] the incoming tasks can choice their method on the basis of task requirement like minimum execution time or cost and then it is prioritized. The algorithm is named as TPD Scheduling Algorithm in which T represents Task Selection, $\mathrm{P}$ is used for Priority (in terms of cost) and D is for Deadline. The proposed model is experimented and evaluated on cloud-sim toolkit. Outcomes validate the accuracy of the framework and show a momentous improvement over other scheduling methods. Quentin Perret [8] CLLF, minimizes the extra-cost implicit from tasks that are executed over a cloud setting by ordering using its laxity and locality. By using CLLF, deadlines is minimized while the total execution time of the job remains in acceptable levels. CLLF is non-optimal distributed scheduler for soft deadline task. It is almost similar to the LLF algorithm but only basic difference is CLLF is non-preemptive in nature. It also manages the locality of task.

\section{COMPARISON BETWEEN DEADLINE SCHEDULING ALGORITHMS}

\begin{tabular}{|c|c|c|c|c|}
\hline $\begin{array}{l}\text { Scheduling } \\
\text { Algorithm }\end{array}$ & $\begin{array}{l}\text { Scheduling } \\
\text { Parameters }\end{array}$ & Findings & Tools & Future Scope \\
\hline $\begin{array}{l}\text { Priority and admission } \\
\text { control Based } \\
\text { Scheduling Algorithm }\end{array}$ & $\begin{array}{l}\text { Cost and } \\
\text { Delay }\end{array}$ & $\begin{array}{l}\text { It is used to optimize time and } \\
\text { achieve high throughput by } \\
\text { providing efficient resources. }\end{array}$ & Experimental Tests & $\begin{array}{c}\text { Model to hire resources from } \\
\text { other clouds and provision of } \\
\text { security to improve the } \\
\text { performance of the cloud } \\
\text { system. }\end{array}$ \\
\hline $\begin{array}{l}\text { Schedule-as-soon-as- } \\
\text { possible Algorithm }\end{array}$ & $\begin{array}{l}\text { Resource } \\
\text { utilization, } \\
\text { time }\end{array}$ & $\begin{array}{l}\text { It is used for three times cost } \\
\text { savings as compared to BRS and } \\
\text { also having good Distribution of } \\
\text { workload onto resources }\end{array}$ & Haizea & $\begin{array}{l}\text { The backfilling algorithm } \\
\text { proposed is not implemented } \\
\text { and tested. }\end{array}$ \\
\hline $\begin{array}{c}\text { Pre-emptive } \\
\text { Scheduling of On-line } \\
\text { Real Time Services } \\
\text { With Task Migration }\end{array}$ & Efficiency, cost & $\begin{array}{l}\text { It aim to minimize the response } \\
\text { time and to improve the } \\
\text { efficiency of the tasks. }\end{array}$ & Experiment & $\begin{array}{l}\text { To decrease the execution } \\
\text { time of pre-empted task. }\end{array}$ \\
\hline $\begin{array}{l}\text { Sporadic tasks } \\
\text { approach with } \\
\text { deadline } \\
\text { Constrains }\end{array}$ & $\begin{array}{l}\text { Response time, } \\
\text { Deadline } \\
\text { constraints }\end{array}$ & $\begin{array}{l}\text { It aims to minimize the response } \\
\text { time and establish lower bound } \\
\text { for dimension of a regional center } \\
\text { (number of resources) in order to } \\
\text { respect the deadline constrains. }\end{array}$ & MONARC 2 & $\begin{array}{l}\text { The tasks' assignment in a } \\
\text { regional center, considering } \\
\text { statistical methods. Also, a } \\
\text { broker architecture and a } \\
\text { communication protocol will } \\
\text { be considered for hybrid } \\
\text { Clouds. }\end{array}$ \\
\hline $\begin{array}{c}\text { Level based } \\
\text { scheduling algorithm }\end{array}$ & Deadline, Cost & $\begin{array}{l}\text { Best resources on public cloud for } \\
\text { cost saving and also completes } \\
\text { workflow execution within } \\
\text { deadlines. }\end{array}$ & Cloud-sim & $\begin{array}{l}\text { Work on full workflow } \\
\text { application to find the } \\
\text { variations of cost and other } \\
\text { measures in real time. }\end{array}$ \\
\hline $\begin{array}{l}\text { TPD Scheduling } \\
\text { Algorithm }\end{array}$ & $\begin{array}{l}\text { Task selection, } \\
\text { Priority, } \\
\text { Deadline }\end{array}$ & $\begin{array}{l}\text { Minimizes execution time and } \\
\text { also reduce the cost. }\end{array}$ & Cloud-sim & $\begin{array}{l}\text { The other factors like type of } \\
\text { task, task length could be } \\
\text { taken into account for proper } \\
\text { scheduling of tasks. }\end{array}$ \\
\hline
\end{tabular}




\begin{tabular}{|c|l|c|c|}
\hline $\begin{array}{c}\text { Cloud Least Laxity } \\
\text { First Scheduling } \\
\text { Algorithm }\end{array}$ & $\begin{array}{l}\text { Execution Time, } \\
\text { Deadline. }\end{array}$ & $\begin{array}{c}\text { To schedule tasks over a cloud } \\
\text { allows to minimize the extra-cost } \\
\text { of each task while the execution } \\
\text { time of the job remains } \\
\text { acceptable }\end{array}$ & $\begin{array}{l}\text { Cloud-sim } \\
\text { Integration of more advance } \\
\text { scheduling managing to } \\
\text { represent the use of deadline } \\
\text { algorithm in dynamic node } \\
\text { formation and aim of } \\
\text { smearing the solution into } \\
\text { large-scale virtualized grids } \\
\text { and inter-cloud scenarios to } \\
\text { discover the efficiency of the } \\
\text { algorithm in highly dynamic } \\
\text { and large-scale cases. }\end{array}$ \\
\hline
\end{tabular}

\section{CONCLUSION}

In cloud computing environment, number of different resources are delivered as a service in the method of virtual machines and these machines are scheduled by scheduling algorithm. Scheduling is the vital matter in the management of application execution in cloud environment. In this paper, deadline scheduling algorithm are deliberated and they all are compared by using different parameters as well as tools. Mostly they all are work on to minimize the execution time, reduces cost and meet the deadline. Therefore, we need to develop scheduling algorithm for cost optimization.

\section{REFERENCES}

[1] Salim Bitam, "Bees Life Algorithm for Job Scheduling in Cloud Computing," in second international conference on communication and information technology, Feb 2012.

[2] Dr. M. Dakshayini, Dr. H. S. Guruprasad, “An Optimal Model for Priority based Service Scheduling Policy for Cloud Computing Environment" International Journal of Computer Applications (0975 - 8887) Volume 32No.9, October 2011.

[3] Amit Nathani, Sanjay Chaudhary, Gaurav Somani, "Policy based resource allocation in IaaS cloud", Future Generation Computer Systems 28, 94-103, Elsevier, June 2011.
[4] R. Santhosh, T. Ravichandran, "Pre-emptive Scheduling of On-line Real Time Services with Task Migration for Cloud Computing", International Conference on Pattern Recognition, IEEE, Feburary 2013.

[5] Florin Pop, Ciprian Dobre, Valentin Cristea, Nik Bessis, "Scheduling of Sporadic Tasks with Deadline Constrains in Cloud Environments", 27th International Conference on Advanced Information Networking and Applications, IEEE, 2013.

[6] Nitish Chopra, Sarbjeet Singh, "Deadline and Cost based Workflow Scheduling in Hybrid Cloud", International Conference on Advances in Computing, Communications and Informatics (ICACCI), IEEE, 2013.

[7] Dr. V.Vaithiyanathan, R.Arvindh Kumar, S.Vignesh, B.Thamotharan, B.Karthikeyan, "An Efficient TPD Scheduling Algorithm for Cloud Environment" International Journal of Engineering and Technology (IJET), Vol 5 No 3 Jun-Jul 2013.

[8] Quentin Perret, Gabriel Charlemagne, Stelios Sotiriadis, Nik Bessis, "A Deadline Scheduler for Jobs in Distributed Systems", 27th International Conference on Advanced Information Networking and Applications Workshops, IEEE pp 757-764, March 2013. 